\title{
Tree Structure in Relation to Performance: Introduction to the Symposium
}

\author{
Richard W. Harris \\ University of California, Davis
}

In developing the structure of a tree, the goals of the tree-fruit grower and the arborist are similar. Each wants a tree that grows relatively fast while young and that will develop a strong limb structure. The tree-fruit grower wants a tree to mature a large crop of quality fruit with minimum, or at least well distributed, labor requirements. The arborist wants a mature tree that safely fulfills its fractional and aesthetic roles in the landscape.

Most trees do not naturally develop the desired structure, for either the fruit grower or the arborist. In order to develop the desired structure we need to understand: a) how trees naturally develop their mature form; b) how conditions and practices influence tree form; and c) how created structure and practices influence performante.

The purpose of this series of symposium papers is to discuss the influence of the structure of a single tree on its performance. 